\title{
Blocking Avoidance and Escape Responses: Relations With Clinically Relevant Behaviors ${ }^{1}$
}

\author{
Juliana Maria Bubna Popovitz \\ Universidade Federal do Paraná, Curitiba-PR, Brazil
}

\author{
Jocelaine Martins da Silveira² \\ Universidade Federal do Paraná, Curitiba-PR, Brazil
}

\begin{abstract}
The current study aims to evaluate the possible effects of interrupting problematic clinically relevant behaviors on the percentage of these responses and of clinical improvement-related responses. Two clients were treated with Functional Analytic Psychotherapy (FAP), alternating two conditions (ABAB). On condition A, procedures to the therapist consisted of responding to the clinical improvement responses, and to description of outside of therapeutic setting behaviors, but therapists were advised to ignore problem behaviors emitted in session. During condition B, therapists followed the same procedures, but they were oriented to block (interrupt) problematic responses emitted in session. Results suggest increase in the percentage of problem behaviors during condition B. Results are discussed, highlighting the viability of planning the contingent response the therapist emits to clinically relevant behaviors.
\end{abstract}

Keywords: therapeutic accompaniment, cognitive behavioral therapy, psychotherapeutic intervention

\section{Bloqueio de Respostas de Evitação e Fuga: Relações com os Comportamentos Clinicamente Relevantes}

\begin{abstract}
Resumo: O presente estudo visa avaliar possíveis efeitos de procedimentos de interrupção de comportamentos clinicamente relevantes problemáticos nas porcentagens de sua emissão e nas de comportamentos de melhora durante a sessão. Duas clientes foram tratadas com a Psicoterapia Analítica Funcional (FAP), alternando duas condições (ABAB). Na condição A, os procedimentos consistiam em responder aos comportamentos de melhora na interação com o terapeuta e aos relatos sobre os comportamentos na vida diária, ignorando os comportamentos problemáticos no contexto da sessão. Na condição B, os procedimentos foram mantidos, mas os comportamentos problemáticos foram interrompidos em vez de ignorados. Os resultados sugerem aumento na porcentagem de comportamentos problemáticos na condição B. Os resultados são discutidos destacando a viabilidade do planejamento de responder do terapeuta contingentemente ao comportamento do cliente.
\end{abstract}

Palavras-chave: acompanhamento terapêutico, terapia cognitivo-comportamental, intervenção terapêutica

\section{El bloqueo de Respuestas de Escape y Evitación: Relaciones con las Conductas Clínicamente Relevantes}

\begin{abstract}
Resumen: El estudio tiene como objetivo evaluar los posibles efectos de la interrupción de las conductas clínicamente relevantes problematicas en los porcentajes de emisión y de conductas de mejora durante la sesión. Dos clientes fueron tratados con la Psicoterapia Analítica Funcional (FAP), alternando dos condiciones (ABAB). En la condición A del tratamiento, los procedimientos consistían en responder a las conductas de mejora en la interacción con el terapeuta y a los informes sobre las conductas en la vida diaria, haciendo caso omiso de los problemas de comportamiento en el contexto de la sesión. En la condición B, los procedimientos se mantuvieron, pero los problemas de conducta fueron interrumpidos en lugar de ignorados. Los resultados sugieren un aumento en el porcentaje de comportamientos problemáticos en la condición B. Los resultados son discutidos, destacando la viabilidad de la planificación del terapeuta de responder de forma contingente al comportamiento del cliente.
\end{abstract}

Palabras clave: acompañamiento terapéutico, terapia cognitiva-conductista, intervención psicoterapéutica

Specific therapist's behaviors in session promote the client's clinical improvement. Particularly on Functional Analytic Psychotherapy (FAP); Kanter, Tsai, \& Kohlenberg,

\footnotetext{
${ }^{1}$ Article derived from the first author's Master's dissertation, produced under the supervision of the second author, defended in 2013 in the Graduate Program in Psychology of the Universidade Federal do Paraná.

${ }^{2}$ Correspondence address: Jocelaine Martins da Silveira. Rua Alfredo Bufren, 50, gabinete 219, Centro. CEP: 80020-240. Curitiba, Paraná, Brazil. E-mail: jocelainesilveira@ufpr.br
}

2010), the therapist's contingent responding is the mechanism of change, which has already been empirically tested and had its efficacy proven (Oshiro, Kanter, \& Meyer, 2012; Xavier, Kanter, \& Meyer, 2012). As a result, describing the contingent responding to clinically relevant behavior (CRBs) might be useful, both for research and practical application of FAP.

FAP emphasizes that the interpersonal problems the client faces in his daily life relationships tend also to happen within the interaction with the therapist (Kohlenberg et al., 2015; Tsai, Callaghan, \& Kohlenberg, 2013; Tsai, Yard, \& 
Kohlenberg, 2014). The case conceptualization establishes the behaviors that may hinder or facilitate the client's relationships (Kanter et al., 2010). Thus, two different types of clinically relevant behaviors (CRBs) are proposed: CRB1s are the client's responses related to his problem or difficulty in his relationships. On the other hand, CRB2s are behaviors related to the client's improvements. This case conceptualization also includes behaviors with the same function as CRBs that occur in the client's daily life. They are called "outside" (O) (Bonow, Maragakis, \& Follette, 2012). The daily life problems reports are registered as $\mathrm{O} 1 \mathrm{~s}$, and daily life goals, as $\mathrm{O} 2 \mathrm{~s}$.

The therapeutic environment is the context where the clinical change happens. Thus, improvements on FAP depend on manipulating the client's behaviors in session (Tsai, Plummer, Kanter, Newring, \& Kohlenberg, 2010). In order to create a therapeutic environment, where CRBs are more likely to occur, allowing the therapist's shaping of CRBs, Tsai et al. (2010) suggest the five therapeutic rules. They advise the therapist to: (1) watch for CRBs, (2) evoke CRBs, (3) respond to CRBs, (4) observe the effect of therapist behavior in relation to client's CRBs and (5) provide functional interpretations of variables and implement generalization strategies.

The FAP logical framework (Weeks, Kanter, Bonow, Landes, \& Busch, 2011) is a step forward in applying the five rules: it describes both therapist and client responses, in such an ideal situation where CRBs are evoked and shaped (Nelson, Yang, Maliken, Tsai, \& Kohlenberg, 2016). This way of expressing the five rules emphasizes the elements in FAP which are involved in the clinical change, e.g., the therapist's responses to CRBs. In this way, it is possible to isolate the therapist's responses, and test hypotheses about its mechanisms.

FAP's logical framework consists of 12 steps, in which the therapist's behaviors and their effects on the client are described. This framework emphasizes the ideal therapist-client interaction, in which CRB1s are shaped into CRB2s. In sum, FAP's logical framework outline is: (1) therapist provides out-to-in parallel, (2) client confirms its accuracy, (3) therapist evokes CRB, (4) client engages in CRB1, (5) therapist contingently responds to CRB1, (6) client engages in CRB2, (7) therapist contingently responds to CRB2, 8) client engages in more CRB2, (9) therapist asks about the effect of interaction on the client, (10) client engages in more CRB2, (11) therapist provides out-to-in parallel and suggests homework, (12) client reports willingness to try homework out of session. Particularly, steps five and seven specify FAP's mechanism of change, which is the therapist contingent responding to CRBs (Busch et al., 2009; Kanter, Tsai, Holman, \& Koerner, 2013). The description "therapist contingently responds to CRBs" recommends that the therapist response must decrease CRB1 frequency and increase CRB2, however, how the therapist can achieve such change is not descibed.

Handling CRB1 is especially difficult, as it should reduce the frequency of some of the client's responses. There are two possible therapist's behaviors: the therapist might ignore CRB1 and differentially respond to other instances of the client's behaviors, such as CRB2s and Os, or the therapist might deliberately interrupt the emission of CRB1 by blocking escape and avoidance responses (Busch et al., 2009; Weeks et al., 2011). Landes, Kanter, Weeks, and Busch (2013) evaluated the effect of evoking behavior, contingently responding to behavior, and generalizing improvement - on individual target variables of clients. They conducted an $\mathrm{A} / \mathrm{A}+\mathrm{B}$ design so that relationship-building aspects of FAP occurred in the A phase and other active components were added in the $\mathrm{A}+\mathrm{B}$ phase. The findings provided support for the hypothesis that FAP's active components caused the desired changes. The authors considered that those data moved the research closer to isolating specific behavioral principles as the mechanism of change in FAP.

The present study aims to evaluate the effects of blocking CRB1 on the frequency of client's responses, particularly CRB1 and CRB2, checking two possible ways of responding to it: by interrupting it, or reinforcing other instances of the client's behaviors. The following relations were investigated, giving the two alternatives of therapist's responding to CRB1: a) percentage of CRB1s and CRB2s; b) transitional probability between therapist's and client's turns, more specifically Os and CRBs, and the respective evocation and contingent responding.

\section{Method}

\section{Participants}

The therapists were two Psychology students, who had experience with Clinical Behavior Analysis and FAP. The clients $(\mathrm{C} 1$ and $\mathrm{C} 2)$ had sought psychological treatment at [Applied Psychology Center located at Federal University of Paraná]. They were invited to participate in the research and agreed to the term of consent. Two client/therapist dyads were designed: Dyad 1 (TR1/C1) and Dyad 2 (TR2/C2). The case conceptualization followed Kanter et al. (2009).

\section{Instruments}

Functional Analytic Psychotherapy Rating Scale FAPRS (Callaghan, Follette, Ruckstuhl, \& Linnerooth, 2008), designed to rate therapist and client behaviors in a FAP-based session. It aims to identify and specify the essential components related to clinical change. The client codes adopted in this research are: CRB1 (clinically relevant behavior related to the client's problem), CRB2 (clinically relevant behavior related to client's progress), $\mathrm{O}$ (description of behaviors outside the therapeutic setting linked either to the client's problem or clinical progress) and CPR (client's positive progression in-session). The codes related to the therapist were: ECRB (therapist evokes a CRB), TCRB1 (therapist responds to a CRB1), TCRB2 (therapist responds to a CRB2), RO (therapist responds to an O), TPR (therapist's positive progress in-session) and $\mathrm{M}$ (therapist misses an opportunity to respond to $\mathrm{CRB}$ ).

The sessions and supervisions were recorded using a Samsung ${ }^{\circledR}$ SMX C-200 digital camera. Coding used a HP® Pavilion dv6 notebook and Windows Media Player®. The following software were used for the statistical analysis: R, SPSS ${ }^{\circledR}$ and Microsoft Office $2010 \circledR$. 


\section{Procedure}

Data collection. The study adopted two conditions called "A" and "B", that were alternated and repeated once each (A1, B1, A2 and B2). Both dyads received the same treatment, which consisted of 11 treatment sessions, plus 4 sessions for case conceptualization. The criteria to switch from one condition to another was a fixed number of sessions, i.e., after three sessions, therapists were instructed to switch to the next planned condition. For both Dyads, sessions 1 to 4 aimed at establishing rapport between therapist and client, and case conceptualization. Starting in session 5, conditions were alternated as follows: Condition A1 (sessions 5 and 6), condition $\mathrm{B} 1$ (sessions 7, 8 and 9), condition A2 (session 10, 11 and 12) and condition B2 (session 13, 14 and 15). The treatment started and was undertaken for both client/therapist dyads in parallel. During conditions A1 and A2, therapists were asked to allow the emission of avoidance and escape CRB1s, without interrupting or deliberately responding to them. At the same time, they were asked to respond differentially to the emission of CRB2s, CRB3s (client interpretations of behavior), $\mathrm{O} 1 \mathrm{~s}$ and $\mathrm{O} 2 \mathrm{~s}$. On conditions $\mathrm{B} 1$ and $\mathrm{B} 2$, therapists were asked to respond to avoidance and escape CRB1s, intentionally interrupting their emission and maintaining the previous procedure regarding CRB2, CRB3, O1 and O2. In order to respond to avoidance $\mathrm{CRB} 1 \mathrm{~s}$, four alternatives of action were suggested to the therapist: a) restate a question or assertion during a client's pause; b) restate a question or assertion interrupting the client; c) describe the effect of the client's behavior on the therapist; d) ask the client to describe his/her own behavior. Prior to the data collection, therapists were trained to identify situations in which they could block avoidance or escape behaviors, and regarding the four alternatives adopted on conditions A1 and A2. The training lasted 40 hours and included role-play and discussion of simulated clinical situations.

Therapists received weekly clinical supervision, in which they discussed the cases and received guidance regarding the subsequent session. All supervision sessions were fully recorded. The supervisor was an experienced therapist (more than 20 years working with behavior therapy and FAP) and her role was to assure the treatment integrity, according to the research design. The sessions were fully recoded. Then, 30 minutes of each session were coded.

Two Psychology major students were trained to rate sessions according to the FAPRS Manual (Callaghan \& Follette, 2008). Raters were aware of the study's hypothesis, but they were blind to the conditions to which the sessions belonged. Interobserver agreement was determined using Cohen's kappa $(k)$ (Cohen, 1960). The values were determined by comparing the researcher, who already had experience with the system, with each of the raters. According to Cohen (1960), values between .41 and .60 are considered fair. This value was considered enough to allow raters to participate in this study. Agreement between raters and the researcher was .57. The rating was simultaneous to the data collecting, on a weekly basis. The unit of analysis was the turn and raters followed the FAPRS manual (Callaghan \& Follette, 2008).
Data analysis. Data are presented separately for each dyad. Analysis of transitional probability of Markov multi-states model (Jackson, 2011) is shown. This analysis aims to verify if there were differences between conditions A1/ $\mathrm{A} 2$ and $\mathrm{B} 1 / \mathrm{B} 2$. Because conditions $\mathrm{A} 1 / \mathrm{A} 2$ and $\mathrm{B} 1 / \mathrm{B} 2$ each followed the same instructions to the therapist, data are presented combining them.

The Markov multi-states model estimates all transitions possibilities among categories, given a matrix of observed transitions. The values indicate the probability of an event $\mathrm{Y}$, given a condition $X$. Thus, the probability of a CRB1 being followed by a $\mathrm{M}$ (miss) is different from the probability of a $\mathrm{M}$ (miss) being followed by a CRB1. The transitional probability adopted in this study takes into account the very next turn in the interaction. That is, immediately after a CRB1, what the most likely therapist response would be. This type of analysis, in the context of this study, is useful because it indicates the difference in the client's responses to each type of intervention.

Finally, the percentage of client and therapist categories is presented. Those values represent the number of occurrences of each code, given the total number of turns in each condition. This analysis helps to observe the clinical change throughout the process. This study did not use comparative statistical analysis due to the limited number of sessions coded, nonetheless, the frequency of each category is presented as a tool to visualize the differences between conditions.

\section{Ethical Considerations}

This study was approved by the Ethics Committee of the School of Health at Federal University of Paraná. All participants signed the informed consent form and all ethical aspects were respected.

\section{Results}

Data were obtained from the rating of 22 sessions, 11 from each dyad. Altogether, 1009 turns were rated: 370 turns from Dyad $1(\mathrm{~T}=185, \mathrm{C}=185)$ and 639 turns from Dyad 2 $(\mathrm{T}=317, \mathrm{C}=322)$. Results are presented separately for each dyad. For each dyad, condition A consisted of five sessions, whereas condition B consisted of six sessions.

\section{Dyad 1}

Table 1 shows the most relevant transition probability in this study for dyad 1. Transitional probabilities were calculated given the total number of transitions in each condition. For Dyad 1, there were 149 transitions for conditions A1/A2 and 197 on conditions B1/B2. For Dyad 1, the transition CRB1-TPR presented the greatest decrease, going from $24.8 \%$ on condition $\mathrm{A} 1 / \mathrm{A} 2$ to $11.6 \%$ on condition $\mathrm{B} 1 / \mathrm{B} 2$. The highest increase was observed on transition CRB1-TCRB1, which changed from $11.1 \%$ to $17.3 \%$. Two transitions decreased from condition A1/A2 to B1/B2: CRB2-TPR (A1/A2 = $16.8 \%, \mathrm{~B} 1 / \mathrm{B} 2=12.3 \%)$ and $\mathrm{RO}-\mathrm{O}(\mathrm{A} 1 / \mathrm{A} 2=13.8 \%, \mathrm{~B} 1 / \mathrm{B} 2$ $=13.6 \%)$. All other transitions increased. 
Table 1

Transitional Probability Analysis for Dyad $1(n=346)$

\begin{tabular}{ccc}
\hline Transition & Condition A1/A2 (\%) & Condition B1/B2 (\%) \\
\hline M-CRB1 & 29.3 & 31.7 \\
ECRB-CRB1 & 28.6 & 30.9 \\
TCRB2-CRB2 & 27 & 28.5 \\
TCRB1-CRB1 & 24.8 & 27.5 \\
CRB1-TPR & 24.4 & 11.6 \\
CRB2-TCRB2 & 18.1 & 21.7 \\
O-RO & 16.5 & 16.1 \\
RO-O & 13.8 & 13.6 \\
CRB1-TCRB1 & 11.1 & 17.3 \\
TCRB1-CRB2 & 7.7 & 10 \\
\hline
\end{tabular}

a)

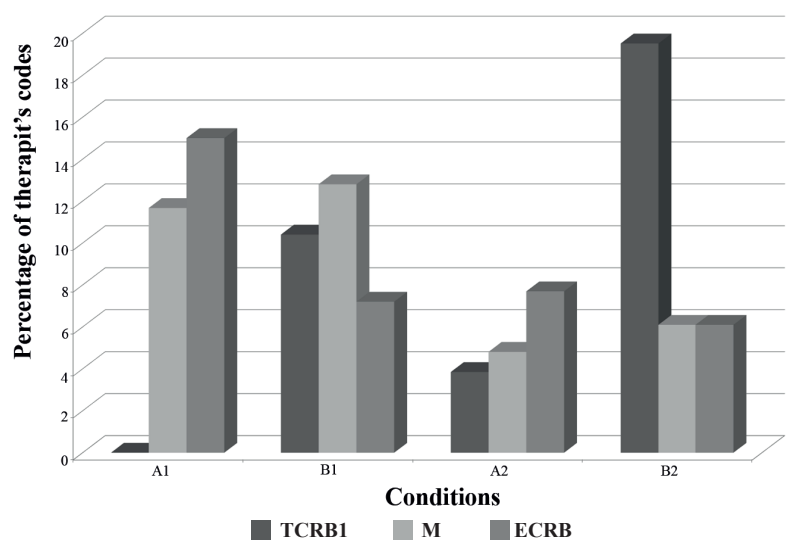

b)

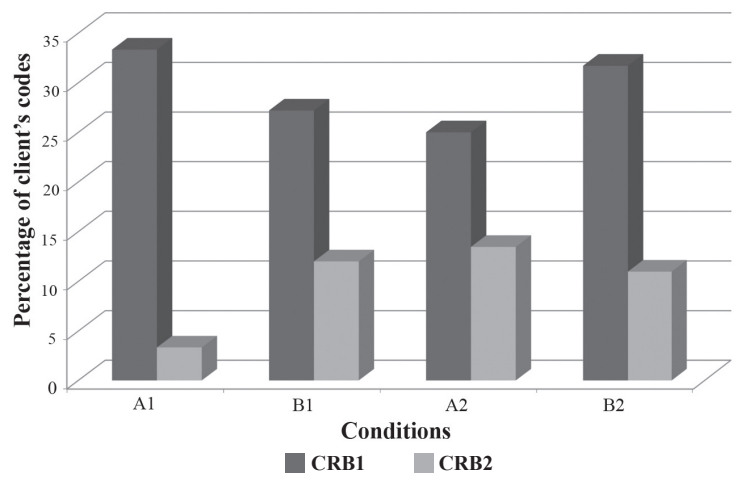

Figure 1. Percentages of occurrence of the main client and therapist codes, throughout the study for Dyad 1.

Figure 1a presents percentages of therapist's categories TCRB1, $\mathrm{M}$ and ECRB. Percentage of ECRB was higher on conditions A1 (15\%) and A2 (7.7\%), compared to conditions $\mathrm{B} 1(7.2 \%)$ and B2 (6.1\%). Percentages of category $\mathrm{M}$ were higher in the first half of the treatment (conditions A1/B1), decreasing in the second half (conditions A2/B2) $(\mathrm{A} 1=12 \%$, $\mathrm{B} 1=13 \% ; \mathrm{A} 2=5 \%, \mathrm{~B} 2=6 \%)$. Percentages of category TCRB1 were higher on conditions $\mathrm{B} 1(10.5 \%)$ and $\mathrm{B} 2(19.5 \%)$, and lower on conditions A1 and A2 ( $0 \%$ and $4 \%$, respectively).

Figure $1 \mathrm{~b}$ shows the percentage for the client's codes. Frequency of CRB1 reduced between conditions A1 (33\%), B1 $(27 \%)$ and A2 (25\%), but increased on condition B2 $(32 \%)$, reaching a similar level to the initial condition. Percentage of CRB2 increased between conditions A1 (3\%), B1 $(12 \%)$ and A2 (13.5\%), but decreased on condition B2 (11\%), remaining on a higher level, compared to the initial condition.

\section{Dyad 2}

Table 2 presents the transition probability of Dyad 2, comparing conditions A1/A2 and B1/B2. For Dyad 2, there were 238 transitions on conditions A1/A2 and 292 on conditions $\mathrm{B} 1 / \mathrm{B} 2$. The most notable variation between conditions happened on transition RO-O, which changed from $21.6 \%$ to $27.9 \%$. Transition CRB1-TCRB1 increased from $14 \%$ to $17.6 \%$. All other transitions remained nearly unchanged between conditions.

Table 2

Transitional Probability Analysis for Dyad $2(n=530)$

\begin{tabular}{ccc}
\hline Transition & Condition A1/A2 (\%) & Condition B1/B2 (\%) \\
\hline M-CRB1 & 35 & 34.9 \\
ECRB-CRB1 & 27.3 & 27.7 \\
TCRB2-CRB2 & 18.3 & 17.8 \\
TCRB1-CRB1 & 34.8 & 33.7 \\
CRB1-TPR & 17.7 & 15.5 \\
CRB2-TCRB2 & 17.2 & 19.6 \\
O-RO & 10.6 & 9.7 \\
RO-O & 21.6 & 27.9 \\
CRB1-TCRB1 & 14 & 17.6 \\
TCRB1-CRB2 & 6.5 & 6.6 \\
CRB1-M & 5.8 & 5.5 \\
\hline
\end{tabular}

Figure 2 shows the percentage of therapist and client's codes in each condition, for dyad 2. Percentage of CRB1 decreased through conditions A1 (32.1\%), B1 (25.8\%) and A2 (13.5\%), going back to a level similar to the initial condition on B2 (30.9\%). Percentage of CRB2, on the other hand, went from $4.6 \%$ on condition $\mathrm{A} 1$, to $7.3 \%$ on condition $\mathrm{B} 1,19.2 \%$ on condition $\mathrm{A} 2$, and decreased to $5.9 \%$ on condition $\mathrm{B} 2$.

Regarding the therapist's codes, category ECRB had the highest percentage on conditions A1 (18.9\%) and A2 (14.9\%). Category TCRB1 was higher on conditions B1 $(12.6 \%)$ and B2 (13.3), compared to conditions A1 (7.7\%) and A2 (3.8\%). Category $\mathrm{M}$ showed higher percentages in the first half of the study $(\mathrm{A} 1=7.7 \%, \mathrm{~B} 1=6.6 \%)$ and decreased in the second half $(\mathrm{A} 2=1 \%, \mathrm{~B} 2=2.7 \%)$. 
a)

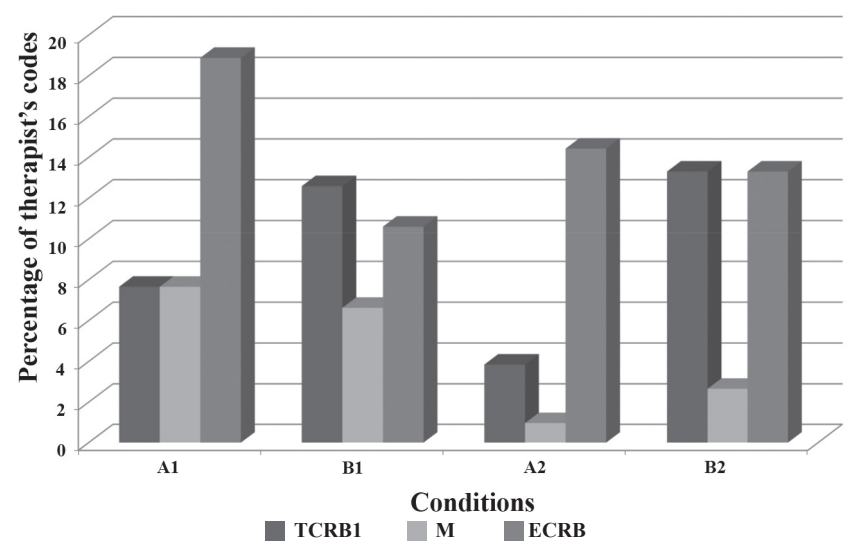

b)

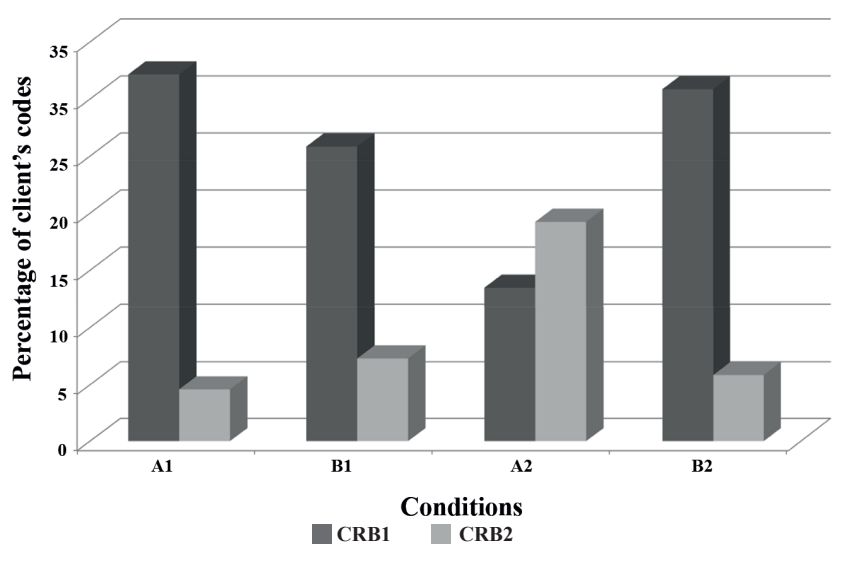

Figure 2. Percentage of Therapist's (a) and Client's (b) Codes for Dyad 2.

\section{Discussion}

The main purpose of this study was to evaluate possible effects of blocking avoidance/escape, adopting CRB1 blocking. Two conditions were planned, such that contingent responses to CRB2 and $\mathrm{O}$ were kept constant and only the responses to CRB1 were manipulated. Even though it is not possible to assure relevant statistical differences between conditions, values from transitional probability analysis suggest the integrity of treatment and indicate possible differences in procedures. Each transition is discussed separately, in order to explore its specific aspects.

M-CRB1: in both dyads, values remained stable between conditions. Regardless of the condition, in about one third of the opportunities the therapist missed CRB1, and client engaged in more CRB1. This result is compatible with Callaghan and Follette (2008) and Callaghan et al. (2008). As suggested by those authors, missing the chance to respond to CRB1 tends to lead to the increase of this response.

ECRB-CRB1: values of this transition remained constant through conditions and dyads. It seems that evoking is more likely to be followed by a CRB1 than by a CRB2, raising the question of its usefulness in modeling CRBs. It is possible that, in this study, therapists evoked CRBs in a way that made emission of CRB1 more likely. Future studies may investigate alternatives of evoking that make CRB2 more likely.
TCRB2-CRB2: although values for Dyad 2 were lower, they were constant between conditions for both dyads. For Dyad 1, in almost one third of the occasions, the client engaged in CRB2 after the therapist reinforced this response. In Dyad 2, CRB2 followed nearly one quarter of TCRB2s. This transition indicates a difference between clients. Giving the case conceptualization for Client 2, in which ignoring the therapist's questions and statements was an instance of CRB1, it is possible to state that the client tended to respond less frequently to the therapist's attempt to reinforce concurrent responses.

TCRB1-CRB1: this transition also showed that constant and high values were noticed between conditions in both dyads. This indicates that, given a contingent response to CRB1, in approximately one third of the occasions, the client kept engaging in this sort of response. This transition suggests a looping between CRB1 and TCRB1 (CRB1-TCRB1-CRB1): given the therapist response to CRB1, it is likely that the client will engage in more CRB1, before switching to a concurrent response. Since the transition ECRB-CRB1 suggested that the evoking is more likely to be followed by a CRB1 than by a CRB2, it is possible to hypothesize that some of the turns categorized as TCRB1 had the function of evoking CRB1.

CRB1-TPR: for both dyads, TPR was more likely to follow a CRB1 on condition A1/A2. This result is probably due to features related to the research design. When therapists allowed the emission of CRB1 (conditions A1/A2), they could respond to the CRB1 through TPR, M or ECRB. Both therapists tended to adopt TPR. Adding to this the fact that the transition CRB1-M had low probability for both dyads, it can be suggested that therapists were efficient in avoiding the unwanted CRB1 reinforcement. Particularly in dyad 1, this transition showed a significant reduction between conditions. On conditions B1/B2, the therapist started responding differently to the client's CRB1s, possibly adopting one of the four alternatives of interrupting CRB1, which lead to the reduction of TPR. On the other hand, therapist 2 tended, even on conditions $\mathrm{A} 1 / \mathrm{A} 2$, to respond more frequently to $\mathrm{CRB} 1$, which explains why transition CRB1-TPR was less likely for Dyad 2 in both conditions. This data suggests that the therapist can plan the way to respond to CRB1.

CRB2-TCRB2: for both dyads, values were stable between conditions. This transition indicates that, in most opportunities, the therapists responded to CRB2 in a way that made this response more probable. Thus, therapists applied step 7 of the FAP logical framework accordingly, regardless of the condition. Step 7 states as a suggestion to the therapist to contingently responds to CRB2. This suggests that procedures proposed by Kohlenberg and Tsai (1991/2007) were adopted.

O-RO and RO-O: these transitions show that, when clients engaged in reporting outside clinical relevant behaviors, therapists tended to keep the focus on these reports. Values for this transition were constant for Dyad 1, between conditions. For Dyad 2, transition RO-O increased on condition $\mathrm{B} 1 / \mathrm{B} 2$. It can be assured that the client kept the focus on outside reports for longer. Given the case conceptualization, it is possible to assume this was a clinical improvement, be- 
cause by reporting outside situations, client gave the therapist the chance to shape the response of expressing and describing feelings.

CRB1-TCRB1: for both dyads, this transition was more likely on conditions B1/B2. Even though this result is insufficient to evaluate the effects of intervention, it suggests the integrity of the treatment, showing that therapists followed the guidance. The therapists responded deliberately to CRB1 on conditions $\mathrm{B} 1 / \mathrm{B} 2$ and allowed occurrence of $\mathrm{CRB} 1$ on condition $\mathrm{A} 1 / \mathrm{A} 2$. A greater difference in these values would be expected from conditions $\mathrm{A} 1 / \mathrm{A} 2$ to $\mathrm{B} 1 / \mathrm{B} 2$, given the change in procedures. One possible explanation for the small difference between conditions is that only the TCRB1s that involved blocking avoidance and escape were rated, leaving out other instances of TCRB1s.

TCRB1-CRB2: for Dyad 1, this transition slightly increased on condition B1/B2, but was constant for Dyad 2 . This result suggests that the contingent response to CRB1 was unlikely to evoke a concurrent response (CRB2), even on conditions $\mathrm{B} 1 / \mathrm{B} 2$, in which the TCRB was expected to affect CRB2 as well as CRB1.

In sum, transitions M-CRB1, ECRB-CRB1, TCRB2-CRB2, CRB1-TCRB1, CRB2-TCRB2, O-RO and RO-O showed that the design was followed as planned. Transitions CRB1-TPR and CRB1-TCRB1 indicated differences between procedures on conditions $\mathrm{A} 1 / \mathrm{A} 2$ versus $\mathrm{B} 1 / \mathrm{B} 2$.

Analysing the transitions, it is not possible to state if the therapist contingent response to CRBs had any effects on them. Nonetheless, regarding the analysis of percentage of responses during the process, some hypotheses can be made. For Dyad 1, the first thing that draws attention is the increase of CRB2 percentage, between conditions A1 and B1. A similar pattern of change is observed in Dyad 2 between conditions B1 and A2. One plausible explanations is that, when the therapists started to respond contingently to CRB1s, the focus on the session switched to the therapeutic relationship, in which the emission of CRB2 became more likely. The delay in this switch, for Dyad 2, may be due to the specificities of the clinical case. As mentioned before, the client tended to ignore the therapist's attempts at shaping concurrent responses.

The increase of CRB1 percentage on condition B2 may be explained by the CRB1-TCRB1-CRB1 looping effect, or by the reintroduction of the intervention. While the therapists went back to responding to CRB1 intentionally and contingently, after a time, when this intervention was withdrawn, the probability of CRB1 increased once more.

In the case of the therapist's codes, evoking CRBs was predominant in conditions A1/A2. This suggests that the therapists already had evoking skills, regardless of the study conditions. It may be hypothesized that evoking CRB2 is an alternative to blocking avoidance and escape behaviors, although it is not clear how to separate evoking CRB1 from evoking CRB2. Esparza Lizarazo, Muñoz-Martínez, Santos, and Kanter (2015), aiming to investigate the isolated effects of FAP's hypothesized mechanism of contingent responding with reinforcement to in-session behavior (Rule 3) from evoking the behavior (Rule 2), conducted an $\mathrm{A} / \mathrm{A}+\mathrm{B}$ design in which the A phase evoked CRB (Rule 2) and the $\mathrm{A}+\mathrm{B}$ phase introduced contingent responding to CRB with reinforcement (Rule 3). Results showed that contingent responding to CRB was related to improvements in CRBs and in out-of-session behaviors for two of the three clients/participants. The improvements were maintained for one client, for whom follow-up data were collected. These results suggest that contingent responding to CRB2 may be related with may be related to increase in evoking response by the therapist. The study conducted by Haworth, Kanter, Tsai, Kuczynski, Rae, and Kohlenberg (2015) also suggests that improvements tend to occur through the reinforcement to CRB2. The study incorporated an experimental procedure that combined providing a brief rationale, asking "closeness-generating" questions to the research participant, shaping vulnerable self-disclosure responses, and providing loving responsiveness to the participants' self-disclosures. The finding indicates that the procedure produced an increasing social connectedness and the sense of connection immediately generalized to others.

Although they refer to different dyads, variation on CRB1 and CRB2 over the sessions seemed to show a pattern. That is, for both dyads, CRB1 was emitted in higher percentages at the first Conditions A, as well as the last condition B, and CRB2 seemed to perform inversely. This pattern can be explained by features related to the process, for instance, at the beginning of the therapeutic process, clients were more prone to emit CRB1, and after the intervention, due to its confrontational characteristic, clients again tended to emit this response as a way of avoiding the therapist's confrontation. In contrast, clients engaged in more CRB2 as the therapeutic process developed and clients improved.

The therapist contingent responding still requires a more through description. Assuming that CRB1 can include escape and avoidance responses, it is plausible to propose blocking strategies. In this study, two conditions were planned, in which therapists had different procedures to respond to CRB1. On condition A, they were asked to respond only to CRB2 and Os. On condition B, they were advised to contingently respond to CRB1, adopting one of four strategies, besides maintaining responses to CRB2 and Os. The goal was to evaluate possible relations of blocking procedures and clinically relevant behaviors.

A few hypotheses can be drawn from the results presented in this study. It is possible that the percentage changes observed in CRB1 and CRB2 were related to the intervention; thus it can be hypothesized that blocking avoidance and escape responses caused the increase on CRB1, as noted on condition B2 for both dyads. Also, it is likely that occurrence of CRB2 increased, as observed on conditions B1 for Dyad 1 and A2 for Dyad 2. Future studies must take into account the cumulative effect of the intervention based on blocking and the possible delay on the clinical change. It is suggested that future researches adopt a B-A-B-A design, so that the cumulative effect and the delay can be better understood. By adopting such design, and its statistical analysis, as Interrupted Time Series Analysis for Single Case Designs, data could be more likely to be understood in terms of separating eventual cumulative effects of therapeutic interventions, i.e., the positive effect of therapeutic process due to the passage of 
time, from the blocking intervention itself (García Jiménez \& Cáceres Serrano, 2007; Harrington \& Velicer, 2015).

It is important to point out that the study could not adopt comparative statistics analysis due to the limited number of sessions. The transitional analysis demanded at least 18 sessions coded with FAPRS, in order to statistically infer if there were significant differences between conditions. Future studies should adopt a larger number of sessions, in order to allow for a more detailed statistical analysis.

One important limitation of this study is that the rate of contingent responding to CRB1 was low in both conditions, specially for Dyad 1. While there is an increase in contingent responding during conditions $\mathrm{B} 1 / \mathrm{B} 2$, it is not possible to infer whether this reduction reached considerable levels, because of the lack of a deeper statistical analysis. Also, a large number of CRB1s were not contingently responded to. A replication of this study should improve the control over the CRB1-TCRB1 transition and could verify whether the hypothesis is valid.

For practical purposes, this study indicates that blocking avoidance and escape may not directly reduce CRB1, but that it might have a deep effect on the clinical improvement, as these procedures affect CRB2 as well. Furthermore, as other studies suggest (Villas-Bôas, Meyer, Kanter, \& Callaghan, 2015), further evaluation could be undertaken, aiming to understand the role of analytic interventions in the increasing or decreasing of CRB1.

\section{References}

Bonow, J. T., Maragakis, A., \& Follette, W. C. (2012). The challenge of developing a universal case conceptualization for functional analytic psychotherapy. International Journal of Behavioral Consultation and Therapy, 7(2-3), 2-8. doi:10.1037/h0100930

Busch, A. M., Kanter, J. W., Callaghan, G. M., Baruch, D. E., Weeks, C. E., \& Berlin, K. S. (2009). A micro-process analysis of functional analytic psychotherapy's mechanism of change. Behavior Therapy, 40(3), 280-290. doi:10.1016/j.beth.2008.07.003

Callaghan, G. M., \& Follette, W. C. (2008). FAPRS Manual: Manual for the Functional Analytic Psychotherapy Rating Scale. The Behavior Analyst Today, 9(1), 57-97.

Callaghan, G. M., Follette, W. C., Ruckstuhl, L. E., \& Linnerooth, P. J. N. (2008). The Functional Analytic Psychotherapy Rating Scale (FAPRS): A behavioral psychotherapy coding system. The Behavior Analyst Today, 9(1), 98-116.

Cohen, J. (1960). A coefficient of agreement for nominal scales. Educational and Psychological Measurement, 20(1), 37-46. doi:10.1177/001316446002000104

Esparza Lizarazo, N., Muñoz-Martínez, A. M., Santos, M. M., \& Kanter, J. W. (2015). A within subjects evaluation of the effects of functional analytic psychotherapy on in-session and out-of-session client behavior. The Psychological Record, 65(3), 463-474. doi:10.1007/s40732-015-0122-7
García Jiménez, M. V., \& Cáceres Serrano, P. A. (2007). Diseños experimenales de series temporales. [Experimental Design of Temporal Series]. Granada: España, UNED.

Harrington, M., \& Velicer, W. F. (2015). Comparing visual and statistical analysis in single-case studies using published studies. Multivariate Behavioral Research, 50(2), 162-183. doi:10.1080/00273171.2014.973989

Haworth, K., Kanter, J. W., Tsai, M., Kuczynski, A. M., Rae, J. R., \& Kohlenberg, R. J. (2015). Reinforcement matters: A preliminary, laboratory-based component-process analysis of functional analytic psychotherapy's model of social connection. Journal of Contextual Behavioral Science, 4(4), 281-291. doi:10.1016/j.jcbs.2015.08.003

Jackson, C. H. (2011). Multi-State Models for panel data: The msm Package for R. Journal of Statistical Software, 38(8), 1-28. doi:10.18637/jss.v038.i08

Kanter, J. W., Tsai, M., Holman, G., \& Koerner, K. (2013). Preliminary data from a randomized pilot study of web-based functional analytic psychotherapy therapist training. Psychotherapy (Chicago), 50(2), 248-255. doi:10.1037/ a0029814

Kanter, J. W., Tsai, M., \& Kohlenberg, R. J. (Eds.). (2010). The practice of functional analytic psychotherapy. New York, NY: Springer.

Kanter, J. W., Weeks, C. E., Bonow, J. T., Landes, S. J., Callaghan, G. M., \& Follette, W. C. (2009). Assessment and case conceptualization. In M. Tsai, R. J. Kohlenberg, J. W. Kanter, B. Kohlenberg, W. C. Follette, \& G. M. Callaghan (Eds.), A guide to functional analytic psychotherapy: Awareness, courage, love and behaviorism (pp. 37-60). New York, NY: Springer.

Kohlenberg, R. J., \& Tsai, M. (2007). Functional analytic psychotherapy: Creating intense and curative therapeutic relationships. New York, NY: Springer. (Original work published 1991)

Kohlenberg, R. J., Tsai, M., Kuczynski, A. M., Rae, J. R., Lagbas, E., Lo, J., \& Kanter, J. W. (2015). A brief, interpersonally oriented mindfulness intervention incorporating functional analytic psychotherapy's model of awareness, courage and love. Journal of Contextual Behavioral Science, 4(2), 107-111. doi:10.1016/j.jcbs.2015.03.003

Landes, S. J., Kanter, J. W., Weeks, C. E., \& Busch, A. M. (2013). The impact of the active components of functional analytic psychotherapy on idiographic target behaviors. Journal of Contextual Behavioral Science, 2(1-2), 49-57. doi:10.1016/j.jcbs.2013.03.004

Nelson, K. M., Yang, J. P., Maliken, A. C., Tsai, M., \& Kohlenberg, R. J. (2016). Introduction to using structured evocative activities in functional analytic psychotherapy. Cognitive and Behavioral Practice, 23(4), 459-463. doi:10.1016/j.cbpra.2013.12.009 
Oshiro, C. K. B., Kanter, J., \& Meyer, S. B. (2012). A single-case experimental demonstration of functional analytic psychotherapy with two clients with severe interpersonal problems. International Journal of Behavioral Consultation and Therapy, 7(2-3), 111-116. http://dx.doi. org/10.1037/h0100945

Tsai, M., Callaghan, G. M., \& Kohlenberg, R. J. (2013). The use of awareness, courage, therapeutic love, and behavioral interpretation in functional analytic psychotherapy. Psychotherapy, 50(3), 366-370. doi:10.1037/a0031942

Tsai, M., Plummer, M. D., Kanter, J. W., Newring, R. W., \& Kohlenberg, R. J. (2010). Therapist grief and functional analytic psychotherapy: Strategic self-disclosure of personal loss. Journal of Contemporary Psychotherapy, 40(1), 1-10. doi:10.1007/s10879-009-91166

Tsai, M., Yard, S., \& Kohlenberg, R. J. (2014). Functional analytic psychotherapy: A behavioral relational approach to treatment. Psychotherapy, 51(3), 364-371. doi:10.1037/ a0036506

Villas-Bôas, A., Meyer, S. B., Kanter, J. W., \& Callaghan, G. M. (2015). The use of analytic interventions in functional analytic psychotherapy. Behavior Analysis: Research and Practice, 15(1), 1-19. doi:10.1037/h0101065

Weeks, C. E., Kanter, J. W., Bonow, J. T., Landes, S. J., \& Busch, A. M. (2011). Translating the theoretical into practical: A logical framework of functional analytic psychotherapy interactions for research, training, and clinical purposes. Behavior Modification, 36(1), 87-119. doi: $10.1177 / 0145445511422830$

Xavier, R. N., Kanter, J. W., \& Meyer, S. B. (2012). Transitional probability analysis of two child behavior analytic therapy cases. International Journal of Behavioral Consultation and Therapy, 7(2-3), 182-188. doi:10.1037/h0100954

Juliana Maria Bubna Popovitz holds a Master's degree from the Graduate Program in Psychology at the Universidade Federal do Paraná.

Jocelaine Martins da Silveira is a professor of the Graduate Program in Psychology at Universidade Federal do Paraná.

Received: Oct. 27, 2015

1st Revision: Apr. 20, 2016

Approved: June 15, 2016

How to cite this article:

Popovitz, J. M. B., \& Silveira, J. M. (2017). Blocking avoidance and escape responses: Relations with clinically relevant behaviors. Paidéia (Ribeirão Preto), 27(67), 20-27. doi: 10.1590/1982-43272767201703 